\title{
Zinc: its impact on immune function in children
}

\author{
Maria Kinash, Oksana Boyarchuk, Lesya Dobrovolska \\ Department of Children's Diseases and Paediatric Surgery, I. Horbachevsky Ternopil National Medical University, Ternopil, Ukraine
}

\section{ABSTRACT}

Based on the analysis of literary sources, this review highlights the main reasons and mechanisms of zinc impact on the development of immunodeficiency conditions in children. The study outlines the importance of zinc homeostasis in the functioning of innate and adaptive immunity. The multifaceted influence of zinc on the activity of the immune system includes the regulation of maturing, differentiation, activity of innate immunity cells (neutrophils, monocytes-macrophages, mast cells, natural killers, dendrite cells) and adaptive immunity cells (T-lymphocytes and B-lymphocytes), activation of interferon synthesis, regulation of the activity of inflammation process, participation in signalling pathways of antigen presentation to the highly specific immune cells, and support of the antioxidant status in the child's organism. The role of zinc status in antiviral immunity, particularly in COVID-19 infection, is considered. A risk group for the development of zinc deficiency and immunodeficiency conditions is identified.

KEY WORDS:

zinc, children, innate immunity, adaptive immunity.

\section{INTRODUCTION}

Microelements are the chemical substances present in human organisms in tiny quantities; their total amount does not exceed $0.005 \%$ of body mass. However, they are essential for the human body's normal functioning and the proper child development because microelements participate in all life processes $[1,2]$. Unlike vitamins, which can be synthesized in human organisms, microelements must be received with food and water. Insufficient intake of microelements with food and water may lead to microelement deficiency and dysfunction of some body systems.

Based on UNICEF data (The State of the World's Children, 1998), microelement deficiency costs countries, on average, nearly $5 \%$ of gross national income. Unfortunately, microelement deficiency manifests subclinically for a long time with no symptoms in both adults and children. The highest importance for maintaining human health is held by essential microelements: calcium, potassium, sodium, chloride, zinc, iodine, chromium, cobalt, manganese, molybdenum, magnesium, copper, selenium, sulphur, and iron [1]. According to the WHO (2009), in many world countries, levels of above listed essential microelements in food intake are marginal, which causes the development of microelement deficiency [3]. One of the most studied essential microelements is zinc $(\mathrm{Zn})$, which is second by quantity in the body. The WHO states that different zinc deficiency stages are present in at least one-third of the world's population. Its expression and distribution depend on the population's geographic location, income, and food traditions, ranging between 10 and $80 \%$ [4]. In particular, based on WHO data, in Eastern European countries approximately $10 \%$ of the population has hypozincaemia [5].

\section{MATERIAL AND METHODS}

A literature search of the PubMed and Scopus databases, regarding the subject of the role of zinc in the human body, using the word "zinc" and the combination

\section{ADDRESS FOR CORRESPONDENCE:}

Lesya Ivanivna Dobrovolska, Department of Children's Diseases and Paediatric Surgery, I. Horbachevsky

Ternopil National Medical University, Ternopil, Ukraine, e-mail: dobrovolska_li@tdmu.edu.ua 
TABLE 1. Mechanism of action of zinc

\begin{tabular}{|c|c|c|}
\hline No & Function & Biological role \\
\hline 1. & Structural & $\begin{array}{l}\text { Component of numerous proteins, including multiple metalloproteins; } \\
\text { biological membranes, }\end{array}$ \\
\hline 2. & Catalytic & Participate in the metabolic processes \\
\hline 3. & Support of reproductive function & $\begin{array}{l}\text { A part of the genetic apparatus of cells, affects the processes of transcription } \\
\text { and replication of DNA and RNA }\end{array}$ \\
\hline 4. & Regulation & $\begin{array}{l}\text { Controls all processes of the cell cycle, provides control of gene expression in } \\
\text { the process of replication and differentiation of cells, regulates the processes } \\
\text { of transcription of other intracellular proteins }\end{array}$ \\
\hline 5. & Neuromodulator and neuromediator & Impact on formation and functioning of the central nervous system \\
\hline 7. & Biosynthesis of bone tissue & $\begin{array}{l}\text { Increases activity of osteoblasts and inhibits osteoclasts' activity, promotes } \\
\text { bone mineralization, affects longitudinal bone growth and skeleton forma- } \\
\text { tion }\end{array}$ \\
\hline 8. & Collagen synthesis & Promotes wound healing \\
\hline 9. & Insulin, testosterone, other hormones biosynthesis & Promotes the normal functioning of the endocrine and reproductive systems \\
\hline 10. & Heme biosynthesis & Normal functioning of erythrocytes; prevents erythrocyte hemolysis \\
\hline 11. & Immune response & Regulation of the processes of innate and acquired immunity \\
\hline 12. & Anti-teratogenic effect & $\begin{array}{l}\text { Promotes growth and development of the fetus; hypozincemia in pregnant } \\
\text { women causes a delay in intrauterine development of the embryo during } \\
\text { the last months of gestation }\end{array}$ \\
\hline 13. & Antioxidative activity & Protection from oxidative damage \\
\hline
\end{tabular}

of the words "zinc" and "immune system", "viral infection", "COVID-19", "supplementation", and "deficiency" was conducted. We used relevant full-text articles, which were published between January 2012 and July 2021. We also used some basic articles, which were published in 1999-2011. Studies with results relating to the role of zinc in the human body, especially in providing an immune response and the possibility of its potential applicability in the prevention and treatment of COVID-19, were selected for analysis.

\section{THE ROLE OF ZINC IN THE HUMAN BODY}

Zinc, being one of the essential microelements, has unique biological importance for the child organism (Table 1):

- It is a part of all enzymatic systems in the organism (zinc-containing enzymes belong to all 6 classes of enzymes, which participate in the metabolic processes and control energy metabolism, DNA and protein biosynthesis, stability of plasma membranes, proliferative processes, degree of development of oxidative stress, sexual differentiation, and physical and neuropsychological child development) $[6,7]$.

- It is a part of more than 300 metalloenzymes such as DNA and RNA polymerase, dehydrogenase, carboxypeptidase, phosphatase, superoxide dismutase, alcohol dehydrogenase, and pyruvate carboxylase, which directly participate in all life processes. In particular, a decrease in zinc level in the human body causes inhibition of the activity of metalloproteinases, which promote inactivation of viral, intracellular, and bac- terial pathogens so that the phagocytosis process is disrupted [8].

- It is a part of the genetic apparatus of cells (zinc-containing proteins are located in the cell nucleus and zinc-containing domains, "zinc fingers", promote binding of the transcription factors to the DNA molecules and promote interaction of proteins with zinc domains with the RNA molecules and other proteins molecules, thus affecting transcription and replication processes [9].

- It controls all processes of the cell cycle (maintains control of gene expression in cell division and cell differentiation processes, so zinc deficiency during embryogenesis can cause the development of defects in the embryo) $[9,10]$.

- It participates in the metabolism of nucleic acids and proteins by being a part of multiple metalloproteins, which regulate transcription and translation of other intracellular proteins. In cells, zinc-dependent proteins are concentrated in the cytoplasm, nucleus, endoplasmic reticulum, Golgi apparatus, and mitochondria $[11,12]$.

- It participates in the stabilization and regulation of permeability of cellular and intracellular membranes, and membrane transport processes by being a part of biological membranes [9].

- It has an impact on formation and functioning of the central nervous system as a neuromodulator and neuromediator [10].

- It participates in the biosynthesis of bone tissue - it increases activity of osteoblasts and inhibits osteo- 
clast activity, promotes bone mineralization and collagen synthesis, and affects longitudinal bone growth and skeleton formation [13]. Zinc deficiency promotes resistance to somatotropin in the child organism [14].

- It is essential for vitamin A metabolism, which has antioxidant properties and protects the organism from oxidative stress [15]. Zinc is a cofactor of the $\beta$-carotin-15,15-dioxygenase enzyme and affects retinol dehydrogenase activity, which both participate in the transformation of carotenoids and vitamin A into their active forms. Besides that, zinc is vital for the synthesis of the apo-retinol binding protein, which is responsible for the transportation of retinol (the active metabolite of vitamin A) to the place of its action in the body [16].

- It participates in the activity of the endocrine system by directly participating in insulin biosynthesis. Adrenocorticotropic hormone, somatotropin, and gonadotropic hormones are also zinc-dependent hormones. Zinc is a part of the nuclear receptor of triiodothyronine and mediates its activity; also, zinc is a part of superoxide dismutase enzyme, deficiency of which promotes thyroid gland hyperplasia [11].

- It plays a vital role in the normal functioning of erythrocytes. Zinc participates in heme biosynthesis, and inhibits phospholipase A2 and adenosine triphosphatase enzymes, which prevents erythrocyte haemolysis $[7,11]$.

- It acts as a teratogenic factor in embryonic development during the early stages of gestation hypozincaemia in pregnant women and causes a delay in intrauterine development of the embryo during the last months of gestation [17].

\section{ANTIOXIDATIVE PROPERTIES OF ZINC}

Zinc actively participates in immune system activity and maintenance of antioxidative status in the child organism $[18,19]$.

In human cells, a significant part (about 20\%) of total intracellular zinc concentration is contained in the metallothionein (MT) proteins that are crucial for the maintenance of $\mathrm{Zn}^{2+}$ homeostasis and free radical oxidative processes. In particular, MT molecules contain a powerful antioxidant, cysteine, and are able to bind and utilize free radicals $[6,20]$. Moreover, MT can interact with and bind other chemical elements such as copper, cadmium, mercury, and arsenic, which have oxidative and toxic properties in relation to biological structures. For stabilization of cellular membranes, it is not only essential to have zinc in their composition but also zinc participation in the protection of these structures from oxidative damage done by reactive oxygen species (ROS). Because zinc is a part of intracellular and extracellular oxidative enzyme $\mathrm{Cu} / \mathrm{Zn}$-superoxide dismutase, the synthesis in- tensity and catalytic activity of which depend on the level and biological accessibility of these microelements, and also inhibits nicotinamide adenine dinucleotide phosphate, which is responsible for ROS production, zinc is an essential antioxidant and plays a significant role in maintaining antioxidative status in the body, which is vital for the child organism because all systems and organs in children are functionally immature and any defects can lead to irreversible processes [11]. Also, zinc antioxidative properties are exhibited in the inhibition of syntheses of inflammatory cytokines (TNF- $\alpha$ and interleukin-1 $\beta$ ), which produce ROS [18]. Thus, zinc plays a significant role in regulating the expression of the activity of the inflammatory process.

Therefore, zinc deficiency is manifested by a decrease in the activity of antioxidant defence processes and the development of oxidative stress in the body.

\section{THE ROLE OF ZINC IN PROVIDING AN IMMUNE RESPONSE}

Zinc plays a critical compartmentalizing role in the functioning of both innate and adaptive immunity. $\mathrm{Zn}^{2+}$ ions actively participate in the normal development, maturing, differentiation, and functioning of myeloid and dendrite cells $[20,21]$ and intensification of the cytotoxic and killer activity of NK-cells [22]. Zinc deficiency inhibits some neutrophil functions, such as phagocytosis, oxidative burst, synthesis of defensins, cation antimicrobial peptides, proteolytic enzymes, and metal chelators, chemotaxis, and formation of extracellular neutrophil trap. It also decreases the production of cytokines [23, 24]. Zinc deficiency also causes mast cell degranulation, which plays a significant role in antiparasitic immunity by releasing histamine, TNF- $\alpha$, and proteases. Hence, it is clear, and evident in multiple studies, that there is incomplete phagocytosis of pathogens by neutrophils during hypozincaemia, which causes infection persistency in the child organism $[23,24]$.

Zinc can block the replicase enzyme of multiple viruses and thus stop the reproduction of the virus in the cells and the development of infection in the human body. In particular, experimental studies in vitro proved that $\mathrm{Zn}^{2+}$ cations, especially in combination with zinc ionophore pyrithione (zinc transporter through the cellular membrane), inhibit the activity of RNA coronavirus RNA polymerase by decreasing its replication $[25,26]$. An important role in destroying intracellular pathogens and transmission of signals to immunocompetent cells belongs to monocytes and macrophages, for differentiation of which zinc is essential. Macrophages can regulate their intracellular zinc level depending on the pathogen, and thus zinc can exhibit a cytotoxic effect on the pathogen (in high concentrations) or stimulate ROS synthesis (during hypozincaemia) and activate free radical oxidation processes towards the pathogen $[27,28]$. 
In studies in vitro and ex vivo, it is evident that zinc can induce production of interferon $a$ and $\gamma$, which increases the antiviral activity of innate immunity. Zinc ions prevent cell apoptosis by inhibiting caspases 3, 6, and 9 and increasing the $\mathrm{Bcl}-2 / \mathrm{Bax}$ ratio. Moreover, zinc ions decrease local signs of inflammation (swelling, exudation, and mucus secretion) by inhibiting the transcapillary movement of plasma proteins to the inflammation site. Multiple studies in vitro and ex vivo showed that extracellular MT exhibits immunomodulatory effects, in particular, increased chemotaxis activity of leucocytes and immunocompetent cells, but as of today, the exact mechanisms of their action are not known. Zinc sequestration done by the human immune system helps to fight extracellular pathogens by expressing pro-inflammatory acute-phase proteins, including IL-6, which increases regulation of expression of zinc-binding peptides - MT and a2-macroglobulins - and stimulates zinc transporter ZIP14, which is embedded into the plasma membrane and facilitates zinc transportation into the cells [29]. Specifically, during the acute phase of inflammation, the biometal blood level decreases because zinc is deposited in tissue cells where inflammation is located, so it is crucial to maintain adequate zinc status in the child organism to ensure the proper response of innate immunity. Besides adequate immune response, zinc is necessary for RNA transcription, DNA synthesis, and cell stabilization $[30,31]$. Thereby, disruption of zinc homeostasis leads to the development of immunodeficiency status in the child, which in the long run will lead to the development of secondary immunodeficiency.

The regulatory function of zinc in adaptive immunity, first of all, is mediated by the thymus hormone thymulin, which contains zinc. Thymulin is necessary for the maturing and differentiation of T-lymphocytes in the thymus. It has been proven that thymulin also affects the proliferation and activation of T-cells in the blood and body tissues [11]. Hypozincaemia leads to the decrease in the number of T- and B-lymphocytes in the thymus and bone marrow, and a change in the Th1- and Th2-lymphocyte ratio in favour of allergic reactions caused by Th2, so maintenance of adequate zinc status will lead to a decrease in allergic reactions in children [32]. Moreover, zinc deficiency decreases allogeneic cytotoxicity and production of IL-2 by T-cells [33-35] and increases B-cell proliferation due to the intensified phosphorylation of STAT3 [36]. Modulation of zinc inhibits MHC-II expression and enhances expression of PD-L1 Ta PD-L2 ligands, which causes a skew in the Treg/Th17 in favour of Treg cell development and a decrease in pro-inflammatory action of Th17 [37]. Hypozincaemia leads to a decrease of lymphoid tissue in the child organism, including premature accidental involution of the thymus, resulting in the development of immunodeficiency of Tand B-cells [11].
In general, zinc promotes the general regulation of immune cell functioning of innate and adaptive immunity by affecting several signalling pathways [23, 35, 38].

The adequate immune response is provided by the coordinated action of innate immune cells, which are the first to react on any microorganism and highly specified adaptive immune cells. Innate immune cells (neutrophils, monocytes, NK-cells, mast cells, and dendrite cells) recognize general pathogen-associated molecular structures with cell-surface recognition receptors, such as Toll-like receptors (TLR), which activate signalling pathways, which induce antigen presentation to highly specific adaptive immune cells and cytokine synthesis and also regulate subsequent antimicrobial actions of naïve cells, such as degranulation, phagocytosis, and pathogen destruction [19, 22, 39]. Transduction of initial signal from the microorganism, detected by the cell-surface receptor of naive cells to the gene expression in the nucleus, is mainly carried out by the phosphorylation processes, which involve the transfer of phosphate groups from one signalling molecule to another through the chain of molecules within a signal transduction pathway. Phosphorylation reactions are catalysed by protein kinases, which are zinc metalloenzymes, so in this way zinc participates in the transformation of extracellular signal into the intracellular signalling event [40]. So, in the absence of zinc signalling, the lytic activity of NK-cells is decreased due to a decrease in recognition of MHC-I antigens on the target cells [11, 41, 42].

One of the main options for triggering the signal of activation of inflammation in the reactions of both innate and adaptive immunity is the NF- $\kappa \mathrm{B}$ factor, activity of which is regulated by phosphorylation reactions and degradation of its specific inhibitor ІкB. It should be noted that zinc-fingered protein A20 causes inhibition of NF- $\kappa B$ and inhibition of expression of IL- $1 \beta$, TNF $\alpha$, $\mathrm{C}$-reactive protein, and other inflammation mediators and thus decreases the level of signalling in the signalling pathways with modulation of zinc status [43-44]. One more zinc-fingered protein, PPAR $\alpha$, changes binding of NFKB with DNA and thus prevents the induction of pro-inflammation cytokines and adhesion molecules and decreases inflammation signs [45]. Hence, maintaining zinc homeostasis in the human body is an essential factor in preventing cytokine storm during the inflammation process.

Considering zinc compartmentalization mechanisms, it should be summarized that zinc is vital for an adequate immune response [46], and its deficiency in the child or adult organism is associated with an immunodeficiency condition [47]. Disruption of zinc status in the blood and/or body cells is observed both during primary (it is part of the metalloenzymes, regulates the production and maturing of immune cells, cytokines, etc.) and secondary immunodeficiencies. For example, we will consider primary immunodeficiency disease - Bruton's disease, 
which is caused by mutations in the gene that codes for Bruton tyrosine kinase and leads to agammaglobulinaemia. As of today, more than 1000 mutations of this gene are known. Due to its functions, Bruton tyrosine kinase belongs to the class of tyrosine protein kinases, which are zinc-containing enzymes that participate in signalling pathways and play an essential role in maturing and functioning of B-lymphocytes. By being a part of this enzyme, zinc participates in maintaining the activity and stability of tyrosine kinase [48]. The absence of Bruton tyrosine kinase is manifested by the significant decrease or total absence of B-lymphocytes, plasma cells, and respectively antigens, leading to severe clinical manifestations of this disease [49-51].

Hypozincaemia causes premature involution of the thymus, a decrease in the mass of lymphoid tissue, lymphocytopaenia, and inhibition of the activity of metalloproteinases, which facilitate inactivation of viral (intracellular) and bacterial (extracellular) pathogens, which in turn can lead to incomplete phagocytosis and microorganism persistency $[11,23,24,40,41,47]$.

\section{ZINC AND COVID-19}

Considering the presence of the coronavirus pandemic at this time, it is worth mentioning the experimental data, which proves that zinc in micromolar concentrations decreases expression of ACE2 zinc-containing metalloenzyme in the lungs with the assistance of which SARS-CoV2 and SARS-CoV can enter the cell [52-53]. As of today, it is well known that in the pathophysiology of most clinical manifestations of COVID-19 active contributions are made by the renin-angiotensin and kinin-kallikrein systems, and that zinc deficiency leads to a decrease of regulation of ACE2, which promotes the accumulation not only of angiotensin II but also of des-Arg-9-bradykinin and Lys-des-Arg9-bradykinin, and causes strengthening of pro-inflammatory reaction, vasoconstriction, and prothrombotic events [54]. Hypozincaemia also promotes dysfunction of cathepsin L, which provokes the development of bradykinin deficiency at the inflammation site and decreases its vasodilatation activity. These effects possibly favour an increase in inflammatory mediator production and a change in anticoagulation parameters in patients with COVID-19. Also, in studies, it was shown that zinc in physiological concentration increases the number, length, and mobility of cilia of mucociliary clearance, which prevents viruses from entering the lower respiratory tract and decreases the risk of secondary bacterial infection, which is crucial for prevention of frequent respiratory tract infections in children [52-54].

Recent results confirm that among women in all trimesters of pregnancy, the blood serum zinc level of pregnant women with COVID-19 was lower than in healthy pregnant women. It negatively correlated with acute-phase inflammatory markers such as IL-6, ESR, procalcitonin, and CRP and correlated with the disease's severity [25].

Conducted studies show that hypozincaemia is considered a risk factor of severe COVID-19 illness [54- 55] and is interpreted as a consequence of zinc deficiency at the level of different metabolic systems that participate in the manifestation of the mentioned disease [56].

For optimization of an adequate zinc level, it is recommended that a daily dose of zinc lower than the permissible upper limits ( $<7 \mathrm{mg}$ for children aged 1-3 years, up to $10 \mathrm{mg}$ at age $4-8$ years, up to $15 \mathrm{mg}$ at age 9-14 years, and up to $22 \mathrm{mg}$ at age 15-17 years) be taken together with nutrition correction. In adults, the recommended daily dose of zinc is $50 \mathrm{mg}$ [57]. However, randomized

TABLE 2. Groups of children at risk of zinc deficiency

\begin{tabular}{|l|}
\hline Condition \\
\hline Premature babies and babies with low body mass or intrauterine growth retardation \\
\hline Recurrent illnesses (secondary immunodeficiencies) \\
\hline Low-income families \\
\hline Vegetarian families and have nutrients deficiency \\
\hline Born from mothers with zinc deficiency \\
\hline Chronic diseases of gastrointestinal and urinary systems \\
\hline Cystic fibrosis or tuberculosis \\
\hline Dermatologic diseases, including allergic dermatitis \\
\hline Delayed physical development and puberty \\
\hline Pathologies of the musculoskeletal system \\
\hline Pathology of the nervous system, including attention deficit hyperactivity disorder \\
\hline Excessive physical and/or psychoemotional load \\
\hline Consumption of water with high iron content \\
\hline Helminthiasis \\
\hline
\end{tabular}


clinical studies did not show any significant decrease in duration of symptoms associated with COVID-19 during treatment of high doses of zinc gluconate, ascorbic acid, and their combination when compared to regular treatment [58]. So, the doses mentioned above are directed to decrease the level of zinc deficiency. It is important to note that the administration of zinc supplementation is based on the presence of zinc deficiency in the blood, and not just belonging to a risk group.

Despite the lack of substantiated recommendations for zinc supplementation for prevention of COVID-19, there are data on the use of zinc for both prevention and treatment of respiratory infections $[59,60]$. The study reported a reduction of the infectious rate after daily zinc intake at a dose of 10-20 mg for 6-12 months [61], so the effectiveness of zinc in the prevention of COVID-19 can be predicted.

\section{RISK GROUPS FOR ZINC DEFICIENCY}

To prevent negative consequences of hypozincaemia, which lead to the development of immunodeficiency in children, it is necessary to measure the zinc concentration in blood in the paediatric population that belong to the risk group. Taking into account the literature data [619], we identified categories of children that should be included in the risk group for the development of hypozincaemia (Table 2).

\section{CONCLUSIONS}

A review of literary sources showed the multifaceted influence of zinc on the activity of the immune system, which includes the regulation of maturing, differentiation, and activity of innate immunity cells (neutrophils, monocytes-macrophages, mast cells, natural killers, dendrite cells) and adaptive immunity cells (T-lymphocytes and B-lymphocytes), activation of synthesis of interferon, regulation of expression of the activity of inflammation process, participation in signalling pathways of antigen presentation to the highly specific immune cells, and support of the antioxidant status of the organism.

\section{DISCLOSURE}

The authors declare no conflict of interest.

\section{REFERENCES}

1. Kontic-Vucinic O, Sulovic N, Radunovic N. Micronutrients in women's reproductive health: II. Minerals and trace elements. Int J Fertil Womens Med 2006; 51: 116-124.

2. Boyarchuk OR, Dobrovolska LI, Kinash MI, et al. Survey assessment of vitamin D and calcium dietary intake in children with somatic pathology. Voprosy pitaniia 2019; 88: 53-62.
3. Tulchinsky TH. Micronutrient Deficiency Conditions: Global Health Issues. Public Health Rev 2010; 32: 243-255.

4. Ezzati M, Lopez AD, Rodgers A, et al. Comparative quantification of health risks: global and regional burden of disease attributable to selected major risk factors. Ezzati M, et al. (eds.). World Health Organization. 2004. Available at: https://apps.who.int/iris/handle/ $10665 / 42770$.

5. Wessells KR, Brown KH. Estimating the Global Prevalence of Zinc Deficiency: Results Based on Zinc Availability in National Food Supplies and the Prevalence of Stunting. PLoS One 2012; 7: e50568.

6. Kimura T, Kambe T. The functions of metallothionein and ZIP and ZnT transporters: an overview and perspective. Int J Mol Sci 2016; 17: 336.

7. Mason JB. Vitamins, trace minerals, and other micronutrients. Goldman LS, Andrew I (eds.). Cecil Medicine. Saunders Elsevier, Philadelphia 2016; 1445-1455.

8. Veropotvelyan PN, Veropotvelyan NP, Kapalina ON, et al. Trace elements and pregnancy. PAH 2012; 2: 95-100.

9. Williams RJ. Zinc in evolution. J Inorg Biochem 2012; 111: 104-109.

10. Velie EM, Block G, Shaw GM, et al. Maternal supplemental and dietary zinc intake and the occurrence of neural tube defects in California. Am J Epidemiol 1999; 150: 605-616.

11. Antonyak GL, Vazhnenko OV, Bovt VD, et al. Biological role of zinc in humans and animals. Biolohiia tvaryn 2011; 13: 17-31.

12. Gammoh NZ, Rink L. Zinc in Infection and Inflammation. Nutrients 2017; 9: 624 .

13. Kim JT, Baek SH, Lee SH, et al. Zinc-deficient diet decreases fetal long bone growth through decreased bone matrix formation in mice. J Med Food 2009; 12: 118-123.

14. Rising R, Scaglia JF, Cole C, et al. Exogenous recombinant human growth hormone effects during suboptimal energy and zinc intake. Nutr Metab (Lond) 2005; 2: 10.

15. Kinash MI, Boyarchuk OR. Fat-soluble vitamins and immunodeficiency: mechanisms of influence and opportunities for use. Vopr Pitan 2020; 89: 22-32.

16. Bhosale P, Larson AJ, Frederick JM, et al. Identification and characterization of a Pi isoform of glutathione S-transferase (GSTP1) as a zeaxanthin-binding protein in the macula of the human eye. J Biol Chem 2004; 279: 49447-49454.

17. Uriu-Adams JY, Keen CL. Zinc and reproduction: effects of zinc deficiency on prenatal and early postnatal development. Birth Defects Res B Dev Reprod Toxicol 2010; 89: 313-325.

18. Prasad AS. Zinc in human health: effect of zinc on immune cells. Mol Med 2008; 14: 353-357.

19. Pecora F, Persico F, Argentiero A, et al. The role of micronutrients in support of the immune response against viral snfections. Nutrients 2020; 12: 3198.

20. Colvin RA, Holmes WR, Fontaine CP, et al. Cytosolic zinc buffering and muffling: their role in intracellular zinc homeostasis. Metallomics 2010; 2: 306-317.

21. Kitamura H, Morikawa H, Kamon H, et al. Toll-like receptor-mediated regulation of zinc homeostasis influences dendritic cell function. Nat Immunol 2006; 7: 971-977.

22. Muzzioli M, Stecconi R, Moresi R, et al. Zinc improves the development of human CD34+ cell progenitors towards NK cells and increases the expression of GATA- 3 transcription factor in young and old ages. Biogerontology 2009; 10: 593-604.

23. Hasan R, Rink L, Haase H. Zinc signals in neutrophil granulocytes are required for the formation of neutrophil extracellular traps. Innate Immun 2013; 19: 253-264.

24. Hasan R, Rink L, Haase H. Chelation of free $\mathrm{Zn}^{2}$ impairs chemotaxis, phagocytosis, oxidative burst, degranulation, and cytokine production by neutrophil granulocytes. Biol Trace Elem Res 2016; 171: 79-88. 
25. Anuk AT, Polat N, Akdas S, et al. The relation between trace element status (zinc, copper, magnesium) and clinical outcomes in COVID-19 infection during pregnancy. Biol Trace Elem Res 2020; 24: 1-10.

26. te Velthuis AJ, van den Worm SH, Sims AC, et al. Zn (2+) inhibits coronavirus and arterivirus RNA polymerase activity in vitro and zinc ionophores block the replication of these viruses in cell culture. PLoS Pathog 2010; 6: e1001176.

27. Subramanian Vignesh K, Landero Figueroa JA, Porollo A, et al. Granulocyte macrophage-colony stimulating factor induced $\mathrm{Zn}$ sequestration enhances macrophage superoxide and limits intracellular pathogen survival. Immunity 2013; 39: 697-710.

28. Botella H, Stadthagen G, Lugo-Villarino G, et al. Metallobiology of host-pathogen interactions: an intoxicating new insight. Trends Microbiol 2012; 20: 106-112.

29. Aydemir TB, Chang SM, Guthrie GJ, et al. Zinc transporter ZIP14 functions in hepatic zinc, iron and glucose homeostasis during the innate immune response (endotoxemia). PLoS One 2012; 7: e48679.

30. Beyersmann D, Haase H. Functions of zinc in signalling, proliferation and differentiation of mammalian cells. Biometals 2001; 14: 331-341.

31. King KL, Cidlowski JA. Cell cycle regulation and apoptosis. Annu Rev Physiol 1998; 60: 601-617.

32. Beck FW, Kaplan J, Fine N, et al. Decreased expression of CD73 (ecto-5'-nucleotidase) in the CD8+ subset is associated with zinc deficiency in human patients. J Lab Clin Med 1997; 130: 147-156.

33. Prasad AS. Effects of zinc deficiency on Th1 and Th2 cytokine shifts. J Infect Dis 2000; 182 Suppl 1: S62-S68.

34. Kahmann L, Uciechowski P, Warmuth S, et al. Zinc supplementation in the elderly reduces spontaneous inflammatory cytokine release and restores T cell functions. Rejuvenation Res 2008; 11: 227-237.

35. Andreini C, Bertini I, Rosato A. Metalloproteomes: a bioinformatic approach. Acc Chem Res 2009; 42: 1471-1479.

36. Gruber K, Maywald M, Rosenkranz E, et al. Zinc deficiency adversely influences interleukin-4 and interleukin-6 signaling. J Biol Regul Homeost Agents 2013; 27: 661-671.

37. George MM, Subramanian Vignesh K, Landero Figueroa JA, et al. Zinc induces dendritic cell tolerogenic phenotype and skews regulatory T-cell-Th17 balance. J Immunol 2016; 197: 1864-1876.

38. Haase, H, Maret, W. The regulatory and signaling functions of zinc ions in human cellular physiology. In: Zalups RK, Koropatnick J (eds.). Cellular and Molecular Biology of Metals; CRC Press: Boca Raton, FL, USA 2009; 181-212.

39. Tartey S, Takeuchi O. Pathogen recognition and Toll-like receptor targeted therapeutics in innate immune cells. Int Rev Immunol 2017; 36: 57-73.

40. Lee EJ, Kim N, Kang KH, et al. Phosphorylation/inactivation of PTEN by Akt-independent PI3K signaling in retinal pigment epithelium. Biochem Biophys Res Commun 2011; 414: 384-389.

41. Kumar S, Rajagopalan S, Sarkar P, et al. Zinc-induced polymerization of killer-cell ig-like receptor into filaments promotes its inhibitory function at cytotoxic immunological synapses. Mol Cell 2016; 62: 21-33.

42. Rolles B, Maywald M, Rink L. Influence of zinc deficiency and supplementation on NK cell cytotoxicity. J Article 2018; 48: 322-328.

43. Morgan CI, Ledford JR, Zhou P, et al. Zinc supplementation alters airway inflammation and airway hyperresponsiveness to a common allergen. J Inflamm (Lond) 2011; 8: 36.

44. Yan YW, Fan J, Bai SL, et al. Zinc prevents abdominal aortic aneurysm formation by induction of A20-mediated suppression of NF- $\kappa$ B pathway. PLoS One 2016; 11: e0148536.

45. Bao B, Prasad AS, Beck FW, et al. Zinc decreases C-reactive protein, lipid peroxidation, and inflammatory cytokines in elderly subjects: a potential implication of zinc as an atheroprotective agent. Am J Clin Nutr 2010; 91: 1634-1641.

46. Maywald M, Wang F, Rink L. Zinc supplementation plays a crucial role in T-helper 9 differentiation in allogeneic immune reactions and non-activated T cells. J Trace Elem Med Biol 2018; 50: 482-488.

47. Wessels I, Maywald M, Rink L. Zinc as a gatekeeper of immune function. Nutrients 2017; 9: 1286.

48. Hyvönen M, Saraste M. Structure of the PH domain and Btk motif from Bruton's tyrosine kinase: molecular explanations for X-linked agammaglobulinaemia. EMBO J 1997; 16: 3396-3404.

49. Boyarchuk O, Dmytrash L. Clinical Manifestations in the Patients with Primary Immunodeficiencies: Data from One Regional Center. Turkish Journal of Immunology 2019; 17: 113-119.

50. Kinash MI, Boyarchuk OR, Hariyan TV, et al. Issues of improving knowledge about primary immunodeficiencies. Vopr prakt pediatr (Clinical Practice in Pediatrics) 2019; 14: 55-62.

51. Boyarchuk O, Balatska N, Chornomydz I. Evaluation of warning signs of primary immunodeficiencies. Pediatria Polska - Polish Journal of Paediatrics 2019; 94: 337-341.

52. Wessels I, Rolles B, Rink L. The Potential Impact of zinc supplementation on COVID-19 pathogenesis. Front Immunol 2020; 11: 1712.

53. Skalny AV, Rink L, Ajsuvakova OP, et al. Zinc and respiratory tract infections: perspectives for COVID-19 (Review). Int J Mol Med 2020; 46: 17-26.

54. Gouda AS, Adbelruhman FG, Elbendary RN, et al. A comprehensive insight into the role of zinc deficiency in the renin-angiotensin and kinin-kallikrein system dysfunctions in COVID-19 patients. Saudi J Biol Sci 2021; 28: 3540-3547.

55. Jothimani D, Kailasam E, Danielraj S, et al. COVID-19: Poor outcomes in patients with zinc deficiency. Int J Infect Dis 2020; 100: 343-349.

56. Yasui Y, Yasui H, Suzuki K, et al. Analysis of the predictive factors for a critical illness of COVID-19 during treatment - relationship between serum zinc level and critical illness of COVID-19. Int J Infect Dis 2020; 100: 230-236.

57. European Commission Health \& Consumer Protection Directorate-General: Scientific Committee on Food; 2003. Opinion of the Scientific Committee on Food on the Tolerable upper Intake Level of Zinc (expressed on 5 March 2003) SCF/CS/NUT/UPPLEV/62 Final. https://ec.europa.eu/food/sites/food/files/safety/docs/scicom_scf_out177_en.pdf.

58. Thomas S, Patel D, Bittel B, et al. Effect of high-dose zinc and ascorbic acid supplementation vs usual care on symptom length and reduction among ambulatory patients with SARS-CoV-2 infection: The COVID A to $\mathrm{Z}$ randomized clinical trial. JAMA Netw Open 2021; 4: e210369.

59. Costagliola G, Spada E, Comberiati P, et al. Could nutritional supplements act as therapeutic adjuvants in COVID-19? Ital J Pediatr 2021; 47: 32.

60. Costagliola G, Nuzzi G, Spada E, et al. Nutraceuticals in Viral Infections: An Overview of the Immunomodulating Properties. Nutrients 2021; 13: 2410.

61. Pecora F, Persico F, Argentiero A, Neglia C, Esposito S. The Role of Micronutrients in Support of the Immune Response against Viral Infections. Nutrients 2020; 12: 3198. 